\title{
Formation and Possible Reactions of Organometallic Intermediates with Active Copper(I) Catalysts in ATRP
}

\begin{tabular}{|r|l|}
\hline Journal: & Organometallics \\
\hline Manuscript ID: & om-2012-006883.R1 \\
\hline Manuscript Type: & Article \\
\hline Date Submitted by the Author: & $26-$ Oct-2012 \\
\hline Complete List of Authors: & $\begin{array}{l}\text { Matyjaszewski, Krzysztof; Carnegie Mellon University, Department of } \\
\text { Chemistry } \\
\text { Konkolewicz, Dominik; Carnegie Mellon University, Chemistry } \\
\text { Schröder, Kristin; Carnegie Mellon University, Chemistry } \\
\text { Poli, Rinaldo; CNRS, Laboratoire de Chimie de Coordination }\end{array}$ \\
\hline
\end{tabular}

\section{SCHOLARONE $^{\text {me }}$ \\ Manuscripts}




\title{
Formation and Possible Reactions of Organometallic
}

\section{Intermediates with Active Copper(I) Catalysts in ATRP}

\author{
Kristin Schröder, Dominik Konkolewicz, Rinaldo Poli, ${ }^{\dagger \ddagger}$ and Krzysztof Matyjaszewski* \\ Department of Chemistry, Carnegie Mellon University, 4400 Fifth Avenue, Pittsburgh, \\ Pennsylvania 15213, USA \\ ${ }^{\dagger}$ Laboratoire de Chimie de Coordination (LCC), CNRS, Université de Toulouse; UPS, INPT, \\ 205, route de Narbonne, 31077 Toulouse, France \\ ${ }^{ \pm}$Institut Universitaire de France, 103, bd Saint-Michel, 75005 Paris, France
}

\begin{abstract}
KEYWORDS: Controlled Radical Polymerization, ATRP, organometallic mediated radical polymerization (OMRP), Catalytic Chain Transfer (CCT), Catalytic Radical Termination (CRT), TPMA.
\end{abstract}

\begin{abstract}
The $\mathrm{Cu}^{\mathrm{I}}$ complex obtained in situ from $\mathrm{Cu}^{\mathrm{I}}$ and tris((4-methoxy-3,5dimethylpyridin-2-yl)-methyl)amine (TPMA*) is currently the most reducing and the most active catalyst for atom transfer radical polymerizations (ATRP). The complex has a high affinity for alkyl halides (ATRP pathway) but also has sufficient affinity towards organic radicals to potentially participate in organometallic mediated radical polymerization (OMRP).
\end{abstract}


Thus, the radical polymerization of $n$-butyl acrylate initiated by AIBN (azobisisobutyronitrile) was significantly retarded and the molecular weights decreased in the presence of the $\mathrm{Cu}^{\mathrm{I}} / \mathrm{TPMA}^{*}$ complex. These results suggest the presence of a $\mathrm{Cu}$-mediated termination processes, even after the amount of radicals generated from AIBN exceeded the initial amount of $\mathrm{Cu}^{\mathrm{I}} / \mathrm{TPMA}^{*}$. Nevertheless, in the presence of alkyl bromides, which act as ATRP initiators for acrylates, control was gained through metal mediated halogen atom transfer, i.e. ATRP, not OMRP.

\section{Introduction}

Conventional radical polymerization (RP) procedures are the most commonly employed industrial techniques for the production of commodity polymers. ${ }^{1}$ RP is characterized by a tolerance to functional groups and many impurities, but provides poor control over polymer architecture, molecular weight $\left(M_{\mathrm{n}}\right)$ and molecular weight distribution $\left(M_{\mathrm{w}} / M_{\mathrm{n}}\right)$. In contrast, reversible-deactivation radical polymerizations (RDRP), ${ }^{2}$ also named controlled/living radical polymerizations (CRP), can provide control over $M_{\mathrm{n}}, M_{\mathrm{w}} / M_{\mathrm{n}}$, and access to polymers with predefined functionalities, compositions, and architectures. ${ }^{3}$ Transition metal-mediated RDRP techniques include atom transfer radical polymerization $(\text { ATRP })^{4}$ and organometallic mediated radical polymerization (OMRP) ${ }^{5}$ They rely on a dynamic equilibrium between a low fraction of growing radicals and a predominant fraction of dormant species.

Since the pioneering work on OMRP by Wayland and co-workers, utilizing cobalt porphyrin complexes for the polymerization of acrylates, ${ }^{6}$ the procedure has been expanded to employ various complexes based on a range of transition metals; e.g. titanium, chromium, iron, cobalt and others, ${ }^{7}$ for a large number of monomers, including vinyl acetate ${ }^{8}$ and acrylamides. ${ }^{9}, 10$ OMRP utilizes a fast reversible homolytic cleavage of a transition metal-carbon bond, Scheme 1. 
OMRP reactions are often initiated by conventional organic radical sources, e.g. azobisisobutyronitrile (AIBN) in the presence of a transition metal complex in its lower oxidation state. The concentration of growing radical chains $\left(\mathrm{P}_{\mathrm{n}}{ }^{*}\right)$ is controlled by a formal reversible one electron process, in which $\mathrm{P}_{\mathrm{n}}{ }^{*}$ reacts with a redox-active transition metal complex $\left(\mathrm{Mt} \mathrm{t}^{\mathrm{n}} \mathrm{L}\right)$, resulting in formation of an oxidized organometallic complex $\left(\mathrm{Mt}^{\mathrm{n}+1}-\mathrm{P}_{\mathrm{n}} / \mathrm{L}\right)$ in the socalled reversible termination process (RT OMRP). The dynamic active/dormant species equilibrium, strongly favoring the dormant state, i.e. $\mathrm{Mt}^{\mathrm{n}+1}-\mathrm{P}_{\mathrm{n}} / \mathrm{L}$, should ensure a low constant concentration of propagating radicals $\left(\mathrm{P}_{\mathrm{n}}{ }^{*}\right)$, allowing a concurrent growth of all polymer chains and minimizing bimolecular termination reactions. Additional control may be provided through a degenerative transfer process (DT OMRP) which involves the reversible associative exchange between $\mathrm{Mt}^{\mathrm{n}+1}-\mathrm{P}_{\mathrm{n}} / \mathrm{L}$ and another propagating radical $\left(\mathrm{P}_{\mathrm{m}}{ }^{*}\right)$, releasing the previous dormant radical $\left(\mathrm{P}_{\mathrm{n}}{ }^{*}\right){ }^{8 \mathrm{a}}$ Consequently, in an OMRP all resulting dormant polymer chains are metalcapped, therefore OMRP requires the presence of stoichiometric amounts of $\mathrm{Mt}^{\mathrm{n}} \mathrm{L}$.

In some cases, catalytic chain transfer (CCT) reactions, Scheme 1, may be involved, especially when using cobalt as the transition metal for the polymerization of methacrylates. ${ }^{8 \mathrm{~b}, 11}$ Formally, $\beta$-hydrogen transfer $\left(k_{\mathrm{CCT}}\right)$ between $\mathrm{P}_{\mathrm{n}}{ }^{*}$ and $\mathrm{Mt}^{\mathrm{n}} \mathrm{L}$ yields an olefin-terminated species $\left(\mathrm{P}^{=}\right)$and a metal hydride complex, $\mathrm{H}-\mathrm{Mt} \mathrm{t}^{\mathrm{n}+1} \mathrm{~L}$. The $\mathrm{H}-\mathrm{Mt}^{\mathrm{n}+1} \mathrm{~L}$ complex reinitiates polymerization of a vinyl monomer forming $\mathrm{Mt}^{\mathrm{n}} \mathrm{L}$ and a propagating radical.

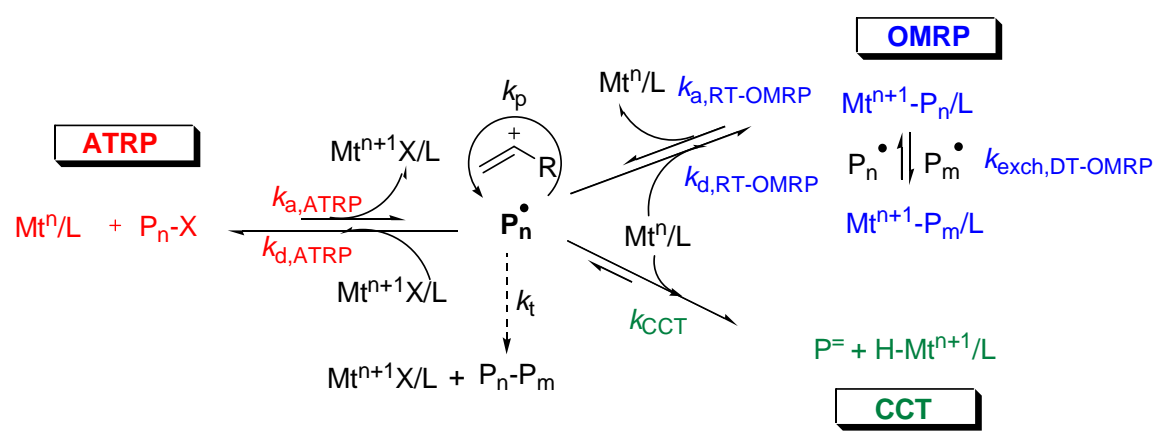

Scheme 1. Schematic illustration of ATRP and OMRP pathways. 
In contrast to OMRP, ATRP gives halogen-capped polymers and is controlled by a fast and reversible homolytic cleavage of a $\mathrm{C}$-halogen bond in a redox reaction with a transition metal catalyst, Scheme 1 , with $K_{\mathrm{ATRP}}=k_{\mathrm{a}, \mathrm{ATRP}} / k_{\mathrm{d}, \mathrm{ATRP}}{ }^{12}$ Since ATRP is a true catalytic process the transition metal complex can be used in sub-stoichiometric concentrations. However, as is the case in OMRP and for the same reasons, the dynamic active/dormant species equilibrium must strongly favor the stable dormant state, in this case $\mathrm{P}_{\mathrm{n}}-\mathrm{X}$. Recent developments in ATRP ${ }^{13}$ e. g., initiators for continuous activators regeneration (ICAR), ${ }^{14}$ target the in-situ regeneration of the activator complex $\left(M^{n} / L\right)$, from the oxidatively stable deactivator complex $\left(M^{n+1} X / L\right)$, formed by unavoidable termination reactions. They allow the transition metal complex to be utilized at parts per million (ppm) concentrations.

Values of $K_{\mathrm{ATRP}}$ can vary over a wide range. ${ }^{15}$ Simply altering the catalyst $\left(\mathrm{Mt}{ }^{\mathrm{n}} \mathrm{L}\right)$ or initiator (R-X) structure provides a powerful tool to influence $K_{\mathrm{ATRP}}$, in each case by more than six orders of magnitude. ${ }^{16}$ Recently, active catalysts for ATRP were developed by incorporating electron donating groups into pyridine based ligand structures such as $2,2^{\prime}$-bipyridine (bpy) ${ }^{17}$ and tris(2pyridylmethyl)amine (TPMA) scaffolds. ${ }^{18}$ Tris((4-methoxy-3,5-dimethylpyridin-2-yl)-methyl)amine (TPMA*) currently provides the most active ligand developed for $\mathrm{Cu}$-catalyzed ATRP.

Part of a quest to develop a deeper understanding of the mechanisms of transition metal mediated CRP has focused on the potential interplay between ATRP, OMRP, and CCT mechanisms. ${ }^{5 \mathrm{a}, 7 \mathrm{~b}}$ ATRP and OMRP can interact synergistically (i.e. the two equilibria, each providing complementary control over the concentration of the propagating radicals) since the ATRP catalyst in the low oxidation state may also act as an OMRP radical trap. Examples of such systems include Mo-mediated, ${ }^{19}$ and Os-mediated ${ }^{20}$ polymerizations conducted with phosphine containing complexes. However, if the equilibria are too strongly displaced towards 
the dormant species, then the one-electron oxidative addition between $\mathrm{Mt}^{\mathrm{n}} / \mathrm{L}$ and $\mathrm{R}-\mathrm{X}$ leading to $\mathrm{Mt}^{\mathrm{n}+1}-\mathrm{X} / \mathrm{L}$ and $\mathrm{Mt}^{\mathrm{n}+1}-\mathrm{R} / \mathrm{L}$ becomes irreversible and, essentially, no polymerization takes place.

OMRP and CCT may competitively interplay, because both processes involve the same reagents $\mathrm{Mt}^{\mathrm{n}} / \mathrm{L}$ and $\mathrm{P}_{\mathrm{n}}{ }^{*}$. The first one leads to reversible metal-carbon bond formation and the second one to $\beta-\mathrm{H}$ atom transfer. The former process can also include $\beta-\mathrm{H}$ elimination from the OMRP dormant species $\mathrm{Mt}^{\mathrm{n}+1}-\mathrm{P}_{\mathrm{n}} / \mathrm{L}$ to yield the same product as in CCT. Such reactions were reported for Mo-mediated polymerizations ${ }^{19 a}$ and Fe-mediated processes with $\alpha$-diimine ${ }^{21}$ or amine-bis(phenolate) ligands. ${ }^{22}$

For Cu-catalyzed ATRP processes, only one report in 1998 pointed to the possibility of an interaction between an organic radical and a copper(I) complex in the absence of halogen atoms. $^{23}$ Diminished polymerization rates for methyl acrylate (MA) initiated by AIBN were observed in the presence of $\mathrm{Cu}$ IOTf complexes with alkyl-substituted bpy ligands. The generation of sufficiently stabilized $\mathrm{RCu}^{\mathrm{II}}$ dormant species is notable, since stable alkyl derivatives of $\mathrm{Cu}^{\mathrm{II}}$ are scarce. ${ }^{24}$ The possibility of a $\beta-\mathrm{H}$ atom transfer process, leading to $\mathrm{Cu}^{\mathrm{II}}-\mathrm{H}$ intermediates has not yet been discussed.

Herein, we investigated the role of $\mathrm{Cu} / \mathrm{TPMA}^{*}$ complexes under ATRP (with R-X) and OMRP (with AIBN) conditions. After the initial evaluation of the effect of $\mathrm{Cu} / \mathrm{TPMA}$ * complexes on $K_{\text {ATRP }}$ under ATRP conditions, ${ }^{18}$ an examination of the effect of the complex under OMRP conditions revealed a significant influence on polymerization rates and molecular weight distributions. The unprecedented contribution of $\mathrm{Cu}$ complexes to catalyzed radical terminations is subsequently critically evaluated.

\section{Results \& Discussion}


$K_{\mathrm{ATRP}}$ and $\boldsymbol{k}_{\mathrm{a}}$ for $\mathrm{Cu} / \mathrm{TPMA} *, \mathbf{C u} / \mathbf{d N b p y}$ and $\mathbf{C u} / \mathbf{b p y}$ : The values of $K_{\mathrm{ATRP}}$ and $k_{\mathrm{a}}$ for the $\mathrm{Cu}^{\mathrm{I}} / \mathrm{TPMA}^{*}$ catalyst complex were determined via stopped-flow measurements using methyl 2bromopropionate (MBP) as an initiator in acetonitrile at $25{ }^{\circ} \mathrm{C} .{ }^{16}$ A value for $K_{\mathrm{ATRP}}$ of $4.2 \times 10^{-4}$ for $\mathrm{Cu} / \mathrm{TPMA}^{* 18}$ was determined from the modified Fischer equation ${ }^{25}$ based on the persistent radical effect (PRE), cf. SI. ${ }^{26}$ The value of $K_{\mathrm{ATRP}}$ obtained for $\mathrm{Cu} / \mathrm{TPMA}^{*}$ is more than five orders of magnitude greater than that determined for $\mathrm{Cu} / \mathrm{dNbpy}$ and six orders of magnitude greater than that measured for the unsubstituted $\mathrm{Cu} / \mathrm{bpy}$ catalyst complex, $K_{\mathrm{ATRP}}=1.0 \times 10^{-9}$ and $K_{\mathrm{ATRP}}=1.3 \times 10^{-10}$, respectively $($ Scheme 2$) .{ }^{16}$

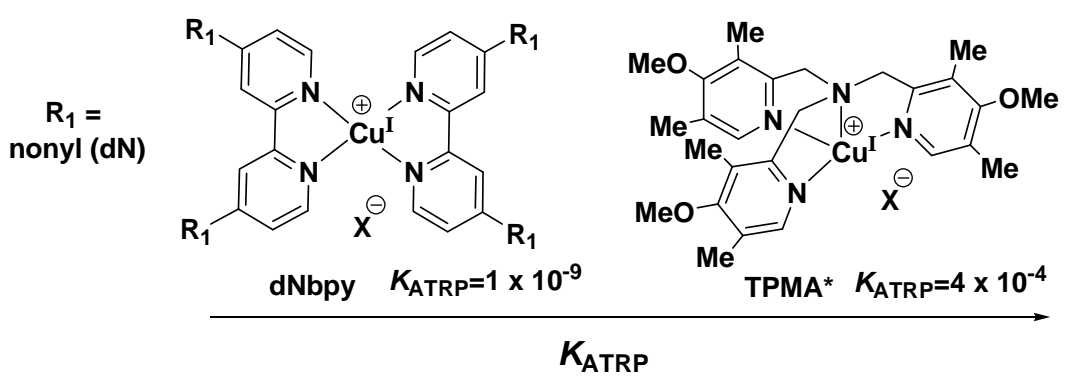

Scheme 2. Effect of ligands on $K_{\mathrm{ATRP}}$ in $\mathrm{Cu}$-catalyzed ATRP processes under the same conditions (MBP, $\left.\mathrm{MeCN}, 25^{\circ} \mathrm{C}\right)$.

An activation rate coefficient $k_{\mathrm{a}, \mathrm{TPMA}^{*}}=8400 \mathrm{M}^{-1} \mathrm{~s}^{-1}$ was determined by trapping the generated methyl 2-propionate radicals with 2,2,6,6-tetramethylpiperidinyl-1-oxy (TEMPO). This value, in comparison with reported values ${ }^{16}$ of $k_{\mathrm{a}, \mathrm{dNbpy}}=3.7 \times 10^{-2} \mathrm{M}^{-1} \mathrm{~s}^{-1}$ and $k_{\mathrm{a}, \mathrm{bpy}}=4.0 \times 10^{-3} \mathrm{M}^{-1} \mathrm{~s}^{-1}$, correlated well with the trend observed for $K_{\mathrm{ATRP}}$. The high activation rate coefficient, combined with the high equilibrium constant indicates that deactivation rate coefficient is sufficiently fast to provide good control in an ATRP $\left(k_{\mathrm{d}, \mathrm{TPMA}^{*}}=2 \times 10^{7} \mathrm{M}^{-1} \mathrm{~s}^{-1}\right)$. 


\section{Normal ATRP and ICAR ATRP of acrylates with Cu/TPMA* in the presence of an alkyl}

halide: First, "normal" and ICAR ATRP were investigated to assess the viability of copper complexes formed with TPMA* for the polymerization of acrylates. The high catalyst loadings in a "normal" ATRP, combined with the very high activity of $\mathrm{Cu}^{\mathrm{I}} / \mathrm{TPMA}^{*}$, initially created very high radical concentrations which resulted in significant termination reactions and relatively poor control. On the contrary, ICAR ATRP, which relies on continuous regeneration of low concentrations of $\mathrm{Cu}^{\mathrm{I}} / \mathrm{TPMA}^{*}$, showed excellent control over $M_{\mathrm{n}}$ with concentrations of catalyst as low as $100 \mathrm{ppm}\left(M_{\mathrm{w}} / M_{\mathrm{n}}=1.15\right)$ down to $5 \mathrm{ppm}\left(M_{\mathrm{w}} / M_{\mathrm{n}}=1.43\right)$, cf. SI Table S1 and Fig. S1. These findings agree with the results of PREDICI ${ }^{\circledR}$ simulations and indicate that very active ATRP complexes are better suited for low ppm ICAR ATRP, rather than normal ATRP. ${ }^{18}$

\section{OMRP initiated by AIBN in the presence of $\mathrm{Cu}^{\mathrm{I}} \mathrm{BF}_{4} / \mathrm{TPMA}^{*}$ in the absence of an alkyl}

halide. The very strongly reducing and active $\mathrm{Cu}^{\mathrm{I}} \mathrm{BF}_{4} / \mathrm{TPMA}^{*}$ complexes could potentially directly interact with propagating radicals. First, control experiments with BA and AIBN under typical conventional radical polymerization conditions were performed and exhibited the expected uncontrolled behaviour with very fast kinetics and broad molecular weight distributions $\left(M_{\mathrm{w}} / M_{\mathrm{n}} \sim 20\right)($ Fig. 1 and $2 \mathrm{~A}$, green $)$.

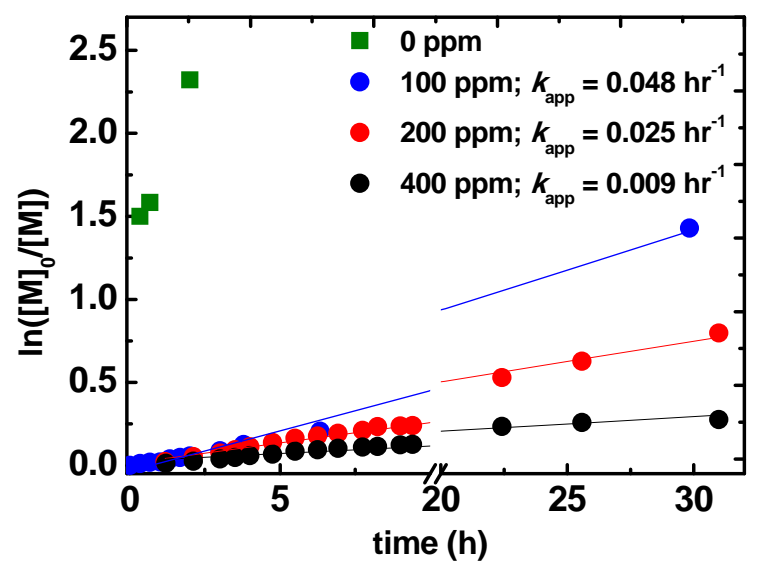


Figure 1. Kinetic plots for polymerization with various loadings of $\left[\mathrm{Cu}^{\mathrm{I}}\right]$; conditions $[\mathrm{BA}]:[\mathrm{AIBN}]:\left[\mathrm{TPMA}^{*}\right]:\left[\mathrm{Cu}^{\mathrm{I}}\left(\mathrm{CH}_{3} \mathrm{CN}\right)_{4} \mathrm{BF}_{4}\right]=[160]:[0.2]:[0.06-0.24]:[0.016-0.064],[\mathrm{BA}]=5.6$ M, 20\% (v/v) anisole, $\mathrm{T}=60^{\circ} \mathrm{C}$.

Then, a series of polymerizations of BA initiated by AIBN in the presence of various concentrations of the $\mathrm{Cu}^{\mathrm{I}} \mathrm{BF}_{4} / \mathrm{TPMA}^{*}$ complex was carried out. The experiments with 100, 200 and $400 \mathrm{ppm} \mathrm{Cu}^{\mathrm{I}}$ were repeated twice, and average values and standard deviation for the pseudo first order kinetic plots are presented in the SI, Tab. S2. In the presence of 100 ppm of $\mathrm{Cu}^{\mathrm{I}} \mathrm{BF}_{4} / \mathrm{TPMA}^{*}$, the rate of polymerization was much slower than in conventional radical polymerization. Conversion increased in a linear fashion in semilogarithmic coordinates and after nearly $30 \mathrm{~h}$ reached only $76 \%$, Fig.1 and SI Fig. S2A. Increasing the amount of $\mathrm{Cu}^{\mathrm{I}}$ complex, to $200 \mathrm{ppm}$ and then to $400 \mathrm{ppm}$ (mol, vs. monomer), resulted in even slower reactions, reaching after $31 \mathrm{~h}$ only $55 \%$ and $25 \%$ monomer conversion, respectively. With [AIBN]:[Cu $\left.{ }^{\mathrm{I}}\right]$ ratio of $1: 1$, corresponding to $1250 \mathrm{ppm} \mathrm{Cu}$ (i.e. under typical OMRP conditions), the polymerization reached only $\sim 2 \%$ after $45.8 \mathrm{~h}$. Assuming a quantitative reaction between $\mathrm{Cu}^{\mathrm{I}}$ and radicals generated from AIBN $(f=0.8)$ to yield an $\mathrm{R}-\mathrm{Cu}$ II $\mathrm{OMRP}$ dormant species, complete consumption of $\mathrm{Cu}^{\mathrm{I}}$ should occur after $1.6 \mathrm{~h}, 3.2 \mathrm{~h}$, and $6.8 \mathrm{~h}$ for systems with $100 \mathrm{ppm} \mathrm{Cu}{ }^{\mathrm{I}}(5 \%$ AIBN consumption), $200 \mathrm{ppm}(10 \%)$ and $400 \mathrm{ppm}$ (20\% AIBN consumption), respectively. This can be determined from the exponential decay in the AIBN concentration over time, $[\mathrm{AIBN}]_{\mathrm{t}}=$ $[\mathrm{AIBN}]_{0} \exp \left(-k_{\mathrm{azo}} t\right)$. Setting the loss of AIBN equal to the initial $\left[\mathrm{Cu}^{\mathrm{I}}\right]$ gives the time $(\mathrm{t})$ needed to react all $\mathrm{Cu}^{\mathrm{I}}$, i.e. $\left[\mathrm{Cu}^{\mathrm{I}}\right]_{0}=2 f\left([\mathrm{AIBN}]_{0}-[\mathrm{AIBN}]_{\mathrm{t}}\right)=2 f[\mathrm{AIBN}]_{0}\left(1-\exp \left(-k_{\mathrm{azo}} t\right)\right)$; $t=-\frac{1}{k_{\text {azo }}} \ln \left(1-\frac{\left[\mathrm{Cu}^{\mathrm{I}}\right]_{0}}{2 f[\mathrm{AIBN}]_{0}}\right)$. However, nearly linear pseudo first-order kinetic plots were observed for more than $30 \mathrm{~h}$, indicating a relatively constant amount of radicals in the system. 
This observation confirms that a radical quenching process must operate not only in the presence of $\mathrm{Cu}^{\mathrm{I}} / \mathrm{TPMA}^{*}$ but also in the presence of the putative $\mathrm{R}-\mathrm{Cu}$ /TPMA* species. The progressive decrease of the apparent propagation rate constants: $k_{\mathrm{app}, 100 \mathrm{ppm}}=0.049 \mathrm{~h}^{-1}, k_{\mathrm{app}, 200 \mathrm{ppm}}=0.017 \mathrm{~h}^{-1}$, $k_{\text {app }, 400 \mathrm{ppm}}=0.008 \mathrm{~h}^{-1}$ follows the amounts of $\mathrm{Cu}^{\mathrm{I}} \mathrm{BF}_{4} / \mathrm{TPMA}^{*}$ (Table S2). In all cases there is a decrease in the rate that is proportional to the concentration of the $\mathrm{Cu}^{\mathrm{I}} \mathrm{BF}_{4} / \mathrm{TPMA}^{*}$, within the standard deviations of the 100, 200 and 400 ppm experiments. This suggests the possibility of radical trapping and/or a catalytic retardation process. It should be stressed that the $k_{\text {app, } 100 p p m}$ for $\mathrm{Cu}^{\mathrm{I}} \mathrm{BF}_{4} / \mathrm{TPMA}^{*}$ was nearly eight times smaller than $k_{\text {app }}$ of the ICAR ATRP reactions using the same amount of $\mathrm{Cu}$ and AIBN but in the presence of alkyl bromides (SI Table S1, entry 5, $\left.k_{\mathrm{app}, 100 \mathrm{ppm}}=0.36 \mathrm{~h}^{-1}\right)$.
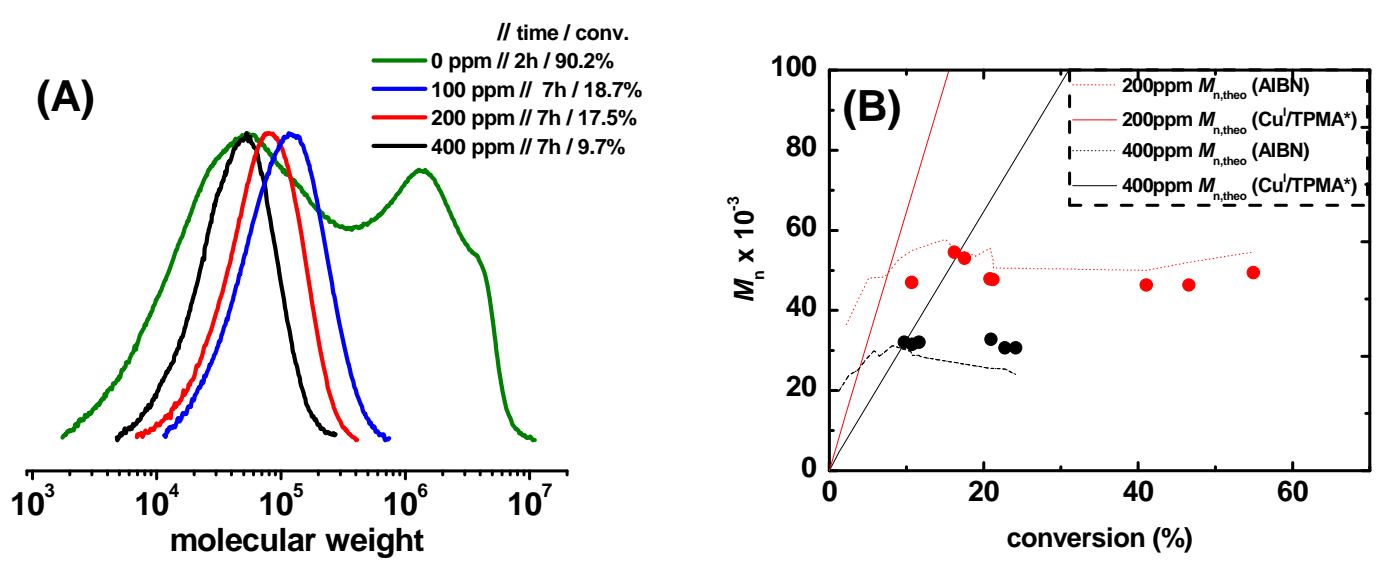

Figure 2. (A) Normalized GPC traces in the presence of $0,100 \mathrm{ppm}, 200 \mathrm{ppm}, 400 \mathrm{ppm}$ $\mathrm{Cu}^{\mathrm{I}} \mathrm{BF}_{4} / \mathrm{TPMA}^{*}$ and (B) $M_{\mathrm{n}, \exp }$ (dots) and $M_{\mathrm{n} \text {,theo }}$ (lines) as function of conversion, parameters and calculation of values for $M_{\mathrm{n} \text {,theo }}(\mathrm{AIBN})$ and $M_{\mathrm{n} \text {,theo }}\left(\mathrm{Cu}^{\mathrm{I}} \mathrm{BF}_{4} / \mathrm{TPMA}^{*}\right)$ are provided in the SI: conditions; [BA]:[AIBN]:[TPMA*]:[C $\left.{ }^{\mathrm{I}}\left(\mathrm{CH}_{3} \mathrm{CN}\right)_{4} \mathrm{BF}_{4}\right]=[160]:[0.2]:[0.06-0.24]:[0.016-0.064]$, $[\mathrm{BA}]=5.6 \mathrm{M}, 20 \%(\mathrm{v} / \mathrm{v})$ anisole, $\mathrm{T}=60^{\circ} \mathrm{C}$. 
Bimodal gel permeation chromatography (GPC) traces for polymer prepared in the conventional radical polymerization reactions were observed (Fig. 2A; SI, Table S3). They could be explained by an initial rapid exothermic polymerization and a two stage process. First, a high molecular weight fraction could be quickly formed in a concentrated monomer solution $\left(M_{\mathrm{n}}=8\right.$ $\mathrm{x} 10^{5}-1 \times 10^{6}$ ). Then, due to the polymerization exothermicity, the temperature could increase, accelerating AIBN decomposition and resulting in a lower molecular weight fraction $\left(M_{\mathrm{n}} \sim 2 \mathrm{x}\right.$ $10^{4}$ ). A temperature probe directly inserted into the reaction mixture showed a temperature increase by $>50^{\circ} \mathrm{C}$ during the polymerization (SI, Fig. S5). Increasing the anisole content to 90 $\%(\mathrm{v} / \mathrm{v})$, slowed down the polymerization and resulted in monomodal distribution, confirming this assumption (SI, Fig. S4). The evolution of $M_{\mathrm{n}}$ and $M_{\mathrm{w}} / M_{\mathrm{n}}$ with conversion in the presence of $\mathrm{Cu}^{\mathrm{I}} \mathrm{BF}_{4} / \mathrm{TPMA}^{*}$ indicated a significant differences compared to conventional RP. The GPC traces (Fig. 2A) of the polymers obtained in the reactions conducted in the presence of $\mathrm{Cu}^{\mathrm{I}} \mathrm{BF}_{4} / \mathrm{TPMA}^{*}$, showed narrower molecular weight distributions (MWD) $M_{\mathrm{w}} / M_{\mathrm{n}} \sim 1.6$ (SI, Fig. S2B). Nevertheless, $M_{\mathrm{n}, \text { exp }}$ did not show a linear increase with conversion (SI, Fig. S2B) and the $M_{\mathrm{n}, \exp }$ values were similar to or lower than the $M_{\mathrm{n}, \text { theo }}$ values, calculated from the actual number of chains generated by the decay of $\mathrm{AIBN}$ (SI, Fig. S3) or the amount of $\mathrm{Cu}^{\mathrm{I}} \mathrm{BF}_{4} / \mathrm{TPMA}^{*}$, respectively. This could suggest the participation of a chain transfer process, although less efficient than in a typical CCT which normally gives oligomers. ${ }^{19 a}$

Potential polymerization mechanisms. Since the radical concentration in the system with $\mathrm{Cu}^{\mathrm{I}}$ is much lower than the conventional $\mathrm{RP}$, a radical trapping by the $\mathrm{Cu}^{\mathrm{I}} \mathrm{BF}_{4} / \mathrm{TPMA}^{*}$ complex is likely. Since an excess of TPMA* was used to insure efficient formation of the $\mathrm{Cu}^{\mathrm{I}} \mathrm{BF}_{4} / \mathrm{TPMA}^{*}$ complex, the ligand itself could also cause retardation. However, a blank experiment with a [TPMA*]:[AIBN] ratio of 0.24:0.2 carried out under conditions similar to those with 400 ppm of 
$\mathrm{Cu}^{\mathrm{I}} \mathrm{BF}_{4} / \mathrm{TPMA}^{*}$ exhibited a conventional RP behaviour with $77 \%$ conversion after $0.5 \mathrm{~h}$ forming a polymer with a broad MWD. In addition, a blank experiment utilizing $\mathrm{Cu}^{\mathrm{I}}\left(\mathrm{CH}_{3} \mathrm{CN}\right)_{4} \mathrm{BF}_{4}$ salt (without TPMA*) also resulted in conventional RP behaviour $(72 \%$ conversion after $0.5 \mathrm{~h}$ with $\left.M_{\mathrm{w}} / M_{\mathrm{n}}=13.6\right)$. This indicates that only the $\mathrm{Cu}^{\mathrm{I}} \mathrm{BF}_{4} / \mathrm{TPMA}^{*}$ complex interferes with the conventional radical chain growth process. Scheme 3 proposes two feasible pathways for the $\mathrm{Cu}$ mediated reactions.

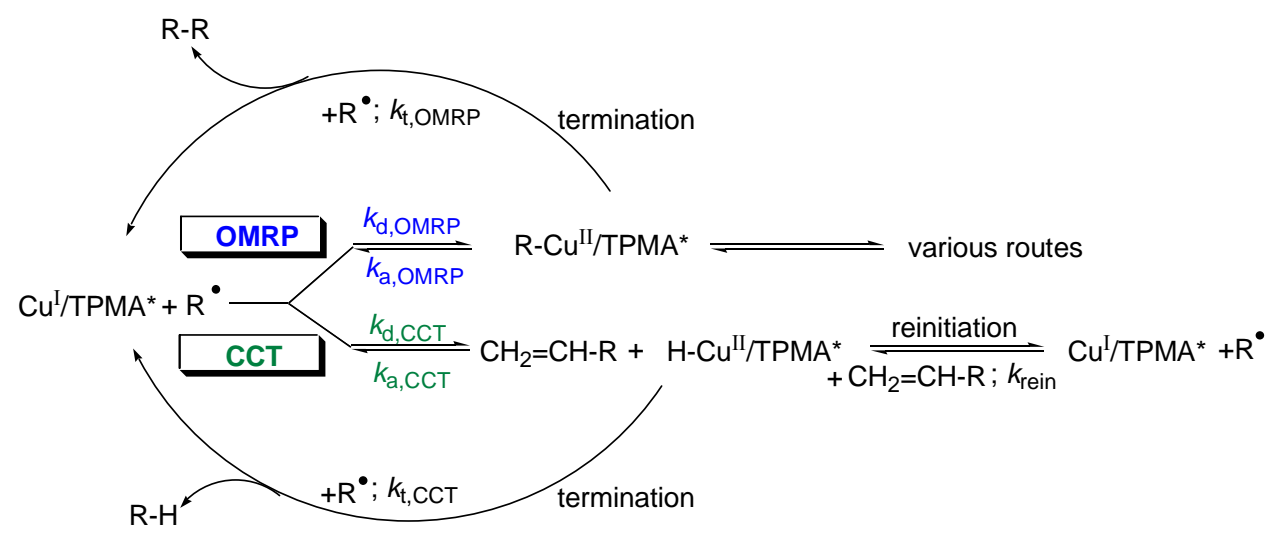

Scheme 3. Possible pathways during the AIBN-initiated polymerization of BA with $\mathrm{Cu}^{\mathrm{I}} \mathrm{BF}_{4} / \mathrm{TPMA}^{*}\left(=\mathrm{Cu}^{\mathrm{I}} / \mathrm{TPMA}^{*}\right)$.

Polymerizations with different initial AIBN concentrations (SI, Fig. S6) were performed in order to define the rate determining step for both pathways. A linear dependence of $k_{\text {app }}$ on the [AIBN] (SI, Fig. S7) was observed. As outlined in the supporting information, this linear dependence of the radical concentration and consequently the polymerization rate, is consistent with slow formation of the $\mathrm{R}-\mathrm{Cu}$ iI intermediates (rate-determining step) followed by fast termination reactions between the $\mathrm{R}-\mathrm{Cu}{ }^{\mathrm{II}}$ intermediates and the propagating radicals. In case of rapid formation of the $\mathrm{Cu}^{\mathrm{II}}$ intermediates, followed by slow termination with propagating radicals, a square root dependence of $k_{\mathrm{app}}$ on the [AIBN] would result. 
In the OMRP scenario, polymerizations in the presence of $\mathrm{Cu}^{\mathrm{I}} \mathrm{BF}_{4} / \mathrm{TPMA}^{*}$ are slower and, consequently, after longer reaction times, a greater number of radicals are generated from AIBN, leading to lower molecular weights. Organometallic copper(II) compounds are intrinsically unstable and therefore rarely studied, ${ }^{27}$ although they were postulated as intermediates in aqueous solutions. $^{28}$ Decomposition of paramagnetic R-Cu ${ }^{\mathrm{II}} / \mathrm{TPMA}^{*}(\mathrm{~S}=1 / 2)$ might take place through termination with another radical $\left(\mathrm{R}^{*}\right)$ to produce $\mathrm{R}-\mathrm{R}$ by recombination and regenerate $\mathrm{Cu}^{\mathrm{I}} / \mathrm{TPMA}^{*}$. Radical-radical coupling processes were previously reported. ${ }^{7 \mathrm{~b}, 24 \mathrm{~b}}$ This pathway is in agreement with observed $M_{\mathrm{w}} / M_{\mathrm{n}} \sim 1.6$ and constant low polymerization rates. Furthermore, decomposition of $\mathrm{R}-\mathrm{Cu} / \mathrm{II} / \mathrm{L}$ can occur via additional routes, i.e.: 1) a one electron reduction processes, yielding a $\mathrm{Cu}^{\mathrm{I}}$ complex and a radical (OMRP reactivation), 2) heterolysis of the carbon-copper bond to give a $\mathrm{Cu}^{\mathrm{II}}$ complex and saturated alkyl species (formed from the carbanion in the presence of $\mathrm{H}_{2} \mathrm{O}$ ), 3) a reductive elimination processes (two electron reduction) yielding $\mathrm{Cu}(0)$, or 4$) \beta$-elimination processes. ${ }^{28}$ The formation of $\mathrm{Cu}(0)$ could be supported by the appearance of small particles in the homogenous polymerization mixture. Note, however, that $\mathrm{Cu}(0)$ can also result from disproportionation.

Another possibility is the formation of an unsaturated alkene and the paramagnetic copper(II) hydride $(\mathrm{S}=1 / 2), \mathrm{H}-\mathrm{Cu}^{\mathrm{II}} / \mathrm{TPMA}^{*}$. The latter can terminate with another radical or reinitiate polymerization with another monomer. Reinitiation would start a CCT polymerization similar to that known for the cobalt/methacrylate systems. ${ }^{11}$ However, the formation of polymers with relatively high molecular weights suggest that the copper hydride intermediate undergoes catalytic radical termination (CRT) with another radical, rather than reinitiation.

PREDICI ${ }^{\circledR}$ simulations. PREDICI ${ }^{\circledR}$ simulations were performed for the two most likely scenarios in order to get further insights into the potential polymerization mechanisms, cf. SI for conditions. First, the OMRP process was considered. Note that, with only deactivation taking 
place, OMRP shows no sustained retardation; the simulations are supplied in the SI (Fig. S8). OMRP including deactivation and termination was simulated $\left(k_{\mathrm{d}, \mathrm{OMRP}}=1.6 \times 10^{5} \mathrm{M}^{-1} \mathrm{~s}^{-1}, k_{\mathrm{t}, \mathrm{OMRP}}\right.$ $=3 \times 10^{8} \mathrm{M}^{-1} \mathrm{~s}^{-1}$, Fig. 3A-C) and the observed retardation agrees well with the experimental data. Furthermore, polymerizations were slow and depended on the amount of $\mathrm{Cu}^{\mathrm{I}} \mathrm{BF}_{4} / \mathrm{TPMA}^{*}$ added to the reaction, while the $M_{\mathrm{w}} / M_{\mathrm{n}}$ values were $\sim 1.5$. Similarly, CRT $\left(k_{\mathrm{d}, \mathrm{CRT}}=1.6 \times 10^{5} \mathrm{M}^{-1}\right.$ $\mathrm{s}^{-1}, k_{\mathrm{t}, \mathrm{CRT}}=3 \times 10^{8} \mathrm{M}^{-1} \mathrm{~s}^{-1}$ ) was considered (Fig. 3D-E). The presence of transfer reactions did not alter the simulated kinetics and molecular weights were in agreement with the experimentally observed values. However, the $M_{\mathrm{w}} / M_{\mathrm{n}}$ values did not decrease below $\sim 2$. Note that the simulations in Fig. 3 D-F are indistinguishable from a pathway resulting in an initial formation of the $\mathrm{R}-\mathrm{Cu}^{\mathrm{II}} / \mathrm{TPMA}^{*}$ organometallic species. This could be followed by rapid $\beta$-elimination to give $\mathrm{H}-\mathrm{Cu}^{\mathrm{II}} / \mathrm{TPMA}^{*}$ and an unsaturated chain, and finally a rapid termination between radicals and the $\mathrm{H}-\mathrm{Cu}$ II $/$ TPMA* to give a dead chain and $\mathrm{Cu}^{\mathrm{I}} / \mathrm{TPMA}^{*}$ (SI, Fig. S9), assuming $k_{\mathrm{d}, \mathrm{OMRP}}=$ $1.6 \times 10^{5} \mathrm{M}^{-1} \mathrm{~s}^{-1}, k_{\beta}=3 \times 10^{8} \mathrm{~s}^{-1}, k_{\mathrm{t}, \mathrm{CRT}}=3 \times 10^{8} \mathrm{M}^{-1} \mathrm{~s}^{-1}$. The concentrations of the various $\mathrm{Cu}$ species under the OMRP or the CRT conditions are given in the SI (Fig. S10). In all cases, Cu concentrations are constant throughout the reaction, and $\left[\mathrm{Cu}^{\mathrm{II}}\right]$ is very low $(\sim 1 \mu \mathrm{M})$, since the reaction between $\mathrm{Cu}^{\mathrm{I}}$ and the propagating radical is the rate limiting step.

(A)

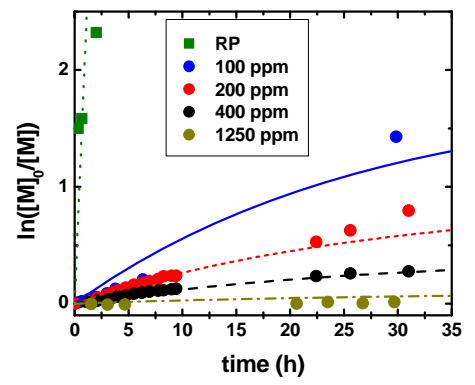

(B)

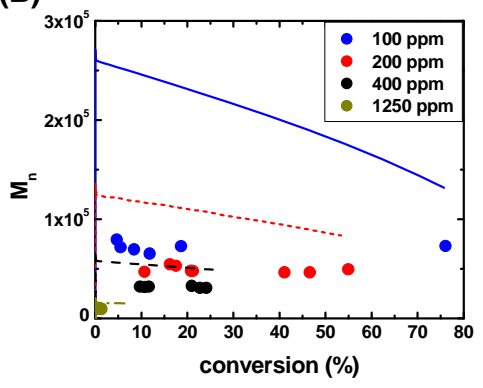

(C)

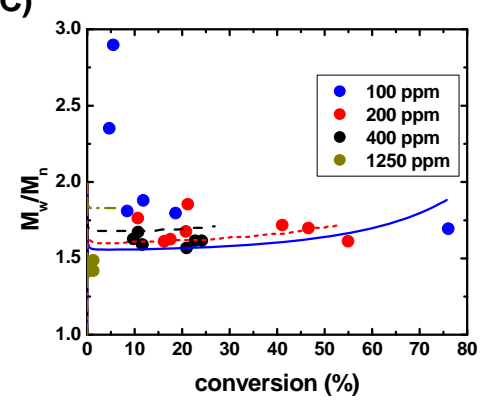


(D)

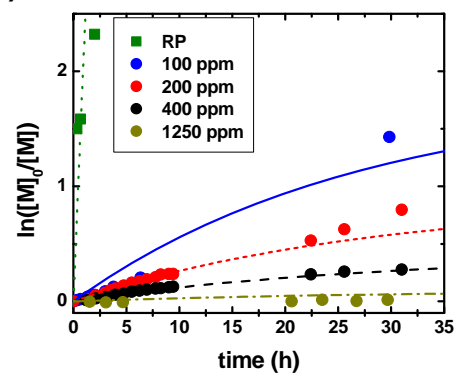

(E)

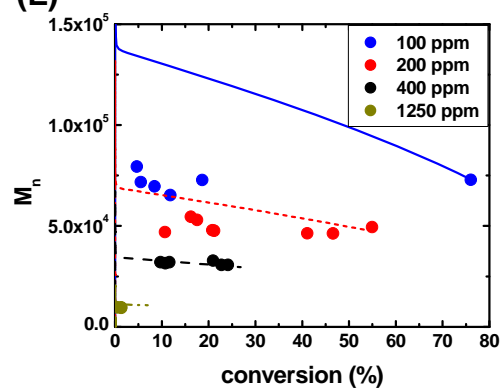

(F)

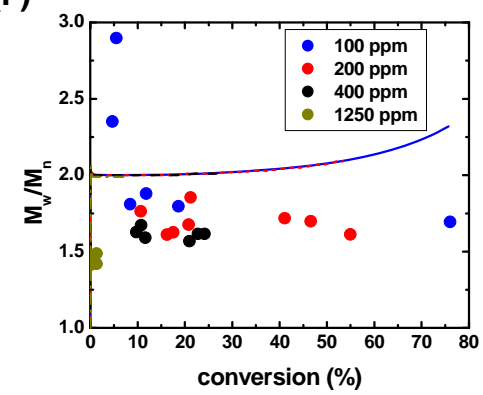

Figure 3. Superposition of simulated (lines) and experimental (circles) data for the polymerization of $\mathrm{BA}$ at various $\left[\mathrm{Cu}^{\mathrm{I}}\right]$ loadings: green, 0 ppm (conventional radical polymerization); blue, 100 ppm; red, 200 ppm; black, 400 ppm; brown, 1250 ppm. (A-C) OMRP with deactivation and termination $\left(k_{\mathrm{d}, \mathrm{OMRP}}=1.6 \times 10^{5} \mathrm{M}^{-1} \mathrm{~s}^{-1}, k_{\mathrm{t}, \mathrm{OMRP}}=3 \times 10^{8} \mathrm{M}^{-1} \mathrm{~s}^{-1}\right)$ : (A) Kinetic plots, (B) $\mathrm{DP}_{\mathrm{n}}$ and (C) $M_{\mathrm{w}} / M_{\mathrm{n}}$ vs. conversion; (D-F) Catalytic radical termination (CRT) $\left(k_{\mathrm{d}, \mathrm{CRT}}=1.6 \times 10^{5} \mathrm{M}^{-1} \mathrm{~s}^{-1}, k_{\mathrm{t}, \mathrm{CRT}}=3 \times 10^{8} \mathrm{M}^{-1} \mathrm{~s}^{-1}\right)$ : (A) Kinetic plots (B), DP $\mathrm{n}_{\mathrm{n}}$ and $(\mathrm{C}) M_{\mathrm{w}} / M_{\mathrm{n}}$ vs. conversion; conditions: $[\mathrm{BA}]:[\mathrm{AIBN}]:\left[\mathrm{Cu}^{\mathrm{I}} / \mathrm{TPMA}^{*}\right]=[160]:[0.2]:[0.016-0.2],[\mathrm{BA}]=5.6 \mathrm{M}, \mathrm{T}$ $=60{ }^{\circ} \mathrm{C}$. Points refer to experimental data, lines refer to kinetic simulations.

Consequences for ATRP: Under the same conditions (temperature, $[\mathrm{AIBN}],[\mathrm{Cu}]$ ), the polymerization is much faster in the presence of $\mathrm{RBr}$ (ICAR ATRP). With $100 \mathrm{ppm}$ $\mathrm{Cu}^{\mathrm{I}} \mathrm{BF}_{4} / \mathrm{TPMA}^{*}$, the apparent rate constant is $k_{\mathrm{app}, 100 \mathrm{ppm}}=0.048 \mathrm{~h}^{-1}$ and in the presence of 100 ppm $\mathrm{Cu}^{\mathrm{II}} \mathrm{Cl}_{2} / \mathrm{TPMA}^{*}$ (and $0.037 \mathrm{M}$ of alkyl bromide) the apparent rate constant is $k_{\mathrm{app}, 100 \mathrm{ppm}}=$ $0.36 \mathrm{~h}^{-1}$. Therefore, the contribution of interactions of radicals with $\mathrm{Cu}^{\mathrm{I}} / \mathrm{TPMA}^{*}$ (retardation) to the overall ICAR ATRP rate is not very significant. Consequently, one can conclude that the control observed under ATRP conditions can be assigned to the ATRP equilibrium. ICAR ATRP of BA with 100 ppm catalyst loading showed excellent agreement between $M_{\mathrm{n} \text {,exp }}$ and $M_{\mathrm{n} \text {,theo, }}$ providing polymers with low values $M_{\mathrm{w}} / M_{\mathrm{n}}=1.15$, whereas the polymerization in the presence of 
$\mathrm{Cu}^{\mathrm{I}} \mathrm{BF}_{4} / \mathrm{TPMA}^{*}$ in the absence of an ATRP initiator showed uncontrolled characteristics, generating polymers with $M_{\mathrm{w}} / M_{\mathrm{n}}=1.88$ after $4 \mathrm{~h}$. Indeed PREDICI ${ }^{\circledR}$ simulations show that under ATRP conditions the polymerization of BA with AIBN at $60^{\circ} \mathrm{C}$ is much better controlled in the presence of RBr (SI, Fig. S11). The modelled system agrees well with the results of reactions performed earlier for butyl acrylate. These simulations showed that in the presence of alkyl halides the rate of polymerization closely matched that of the RP process, regardless of whether the system was initiated in the presence of $\mathrm{Cu}^{\mathrm{I}}$ or $\mathrm{Cu}^{\mathrm{II}}$. In both cases control over the molecular weight was very good. Furthermore, inclusion of either OMRP followed by termination of the organometallic species, or CRT of the $\mathrm{Cu}^{\mathrm{II}}$ hydride, into this ATRP scheme resulted in minimal impact in terms of the polymerization rate or controllability. In contrast, in the absence of $\mathrm{RBr}$, only the OMRP or CRT pathways are possible and the rate of polymerization is decreased, as well as the control over the polymerization. This difference is due to the fact that the ATRP equilibrium shifts nearly all $\mathrm{Cu}^{\mathrm{I}}$ species to $\mathrm{X}-\mathrm{Cu}^{\mathrm{II}}$, effectively removing the majority of the $\mathrm{Cu}^{\mathrm{I}}$ complex that can terminate propagating chains, from the reaction medium. However, due to the high activity of the TPMA* based catalyst complexes, the minute amounts of $\mathrm{Cu}^{\mathrm{I}}$, are still very active in ATRP, and the low mole fractions are sufficient for the continuous reactivation of dormant species.

\section{Comparison with previously observed interactions with $\mathrm{Cu} / \mathrm{dTbpy}$ and $\mathrm{Cu} / \mathrm{dNbpy}$ : The}

AIBN-initiated polymerization of $\mathrm{MA}$ in the presence of $\mathrm{Cu}$ ITf/dTbpy reduced the polymerization rates. ${ }^{23}$ While the polymerization conditions used in the present work were similar to those of the previous report (for a detailed comparison, see SI Table S4), there was a much larger decrease in the polymerization rate for a polymerization of $\mathrm{BA}\left(k_{\mathrm{p}, 60^{\circ} \mathrm{C}}=33700\right.$ $\left.\mathrm{Lmol}^{-1} \mathrm{~s}^{-1}\right)^{29}$ conducted in the presence of $\mathrm{Cu}^{\mathrm{I}} \mathrm{BF}_{4} / \mathrm{TPMA}^{*}(8.5 \%$ conversion after $3 \mathrm{~h})$ than for 
the polymerization of MA $\left(k_{\mathrm{p}, 60^{\circ} \mathrm{C}}=33100 \mathrm{Lmol}^{-1} \mathrm{~s}^{-1}\right)^{29}$ in the presence of CuIf OTf/dTbpy $(\sim 35 \%$ conversion after $3 \mathrm{~h}$ ), although solvent effects can also have some contributions. ${ }^{15 \mathrm{~d}}$ There were also significant differences in the resulting $M_{\mathrm{n}}$ and $M_{\mathrm{w}} / M_{\mathrm{n}}$ values. While the $M_{\mathrm{n}}$ values for the PMA polymers formed in the presence of the $\mathrm{Cu}^{\mathrm{I} O T f} / \mathrm{dTbpy}$ complex were $\sim 2 \times 10^{5}$, the PBA polymers obtained in the presence of $\mathrm{Cu}^{\mathrm{I}} \mathrm{BF}_{4} / \mathrm{TPMA}^{*}$ had $M_{\mathrm{n}}$ values $\sim 3 \times 10^{4}$. These results suggest that the substantially more reducing and more active $\mathrm{Cu}^{\mathrm{I}} \mathrm{BF}_{4} / \mathrm{TPMA}^{*}$ ATRP catalyst interacts with the growing acrylate radicals stronger than the less active $\mathrm{Cu}$ ITf/dTbpy complex.

Conclusions: Interactions between radicals and highly active ATRP complexes $\left(\mathrm{Cu}^{\mathrm{I}} \mathrm{BF}_{4} / \mathrm{TPMA}^{*}\right)$ were observed in the polymerization of acrylates. These interactions led to significantly slower polymerizations, lower molecular weights and narrower molecular weight distributions. This suggests that OMRP trapping processes contribute to retarding the polymerization and preventing the initial formation of polymers with very high molecular weights. Furthermore, the experiments described here also demonstrate the existence of additional termination processes, in the presence of the $\mathrm{Cu}^{\mathrm{I}} \mathrm{BF}_{4} / \mathrm{TPMA}^{*}$ complex, that ultimately quench the free radicals generated by excess AIBN. These reactions may include radical addition to the OMRP dormant species $\mathrm{R}-\mathrm{Cu}{ }^{\mathrm{II}} / \mathrm{TPMA}^{*}$, to generate $\mathrm{R}-\mathrm{R}$ coupling products, and/or addition to the $\mathrm{H}-\mathrm{Cu}{ }^{\mathrm{II}} / \mathrm{TPMA}^{*}$ hydride intermediate of a CRT process to generate $\mathrm{R}-\mathrm{H}$, as shown in Scheme 3. PREDICI simulations confirmed the possibility of $\mathrm{R}-\mathrm{Cu}{ }^{\mathrm{II}} / \mathrm{TPMA}$ * or $\mathrm{H}-$ $\mathrm{Cu}^{\mathrm{II}} / \mathrm{TPMA}^{*}$ formation, followed by a termination reaction with another radical to give $\mathrm{Cu}^{\mathrm{I}} / \mathrm{TPMA}^{*}$ and the recombination product. Further investigations are planned to elucidate this mechanistic question. Nevertheless, in the presence of ATRP initiators, the ATRP equilibrium is primarily responsible for exercising control over the polymerization procedure and dominates over the OMRP processes. 


\section{ASSOCIATED CONTENT}

Supporting Information. "This material is available free of charge via the Internet at

http://pubs.acs.org."

\section{AUTHOR INFORMATION \\ Corresponding Author \\ * Email:km3b@andrew.cmu.edu.}

\section{Author Contributions}

The manuscript was written through contributions of all authors. All authors have given approval to the final version of the manuscript.

\section{ACKNOWLEDGMENT}

The authors would like to thank the CRP Consortium at Carnegie Mellon University and NSF (CHE-1026060, CHE-1039870, CHE-0130903) for financial support and Dr. Johannes Buback for his help with the stopped-flow measurements. K.S. thanks the Deutsche Forschungsgemeinschaft (DFG) for her postdoctoral fellowship (SCHR 1314). R.P thanks the Agence National de la Recherche (project OMRP, grant ANR 2010 BLANC 7101).

\section{REFERENCES}

1. (a) Matyjaszewski, K.; Davis, T. P., Handbook of Radical Polymerization. WileyInterscience: Hoboken, 2002; p 936 pp;(b) Moad, G., Radical Polymerization in Polymer Science: A Comprehensive Reference, Matyjaszewski, K.; Möller, M., Eds. Elsevier: Amsterdam, 2012; Vol. 3, pp 59.

2. Jenkins, A. D.; Jones, R. G.; Moad, G. Pur. Appl. Chem. 2010, 82, 483. 
3. (a) Coessens, V.; Pintauer, T.; Matyjaszewski, K. Prog. Polym. Sci. 2001, 26, 337;(b) Matyjaszewski, K.; Davis, K. A., Statistical, Gradient and Segmented Copolymers by Controlled/Living Radical Polymerizations. Springer Verlag: Berlin, 2002; p 203 pp;(c) Tsarevsky, N. V.; Matyjaszewski, K. Chem. Rev. 2007, 107, 2270;(d) Matyjaszewski, K.; Tsarevsky, N. V. Nat. Chem. 2009, 1, 276;(e) Wang, Y.; Matyjaszewski, K. Macromolecules 2011, 44, 1226;(f) Matyjaszewski, K. Macromolecules 2012, 45, 4015.

4. di Lena, F.; Matyjaszewski, K. Prog. Polym. Sci. 2010, 35, 959.

5. (a) Poli, R. Angew. Chem. Int. Ed. 2006, 45, 5058;(b) Poli, R., Organometallic Mediated Radical Polymerization in Polymer Science: A Comprehensive Reference, Matyjaszewski, K.; Möller, M., Eds. Elsevier BV: Amsterdam, 2012; Vol. 3, pp 351.

6. Wayland, B. B.; Poszmik, G.; Mukerjee, S. L.; Fryd, M. J. Am. Chem. Soc. 1994, 116, 7943.

7. (a) Smith, K. M.; McNeil, W. S.; Abd-El-Aziz, A. S. Macromol. Chem. .Phys. 2010, 211, 10;(b) Poli, R. Eur. J. Inorg. Chem. 2011, 2011, 1513;(c) Hurtgen, M.; Detrembleur, C.; Jerome, C.; Debuigne, A. Polym. Rev. 2011, 51, 188;(d) Allan, L. E. N.; Perry, M. R.; Shaver, M. P. Prog. Polym. Sci. 2012, 37, 127.

8. (a) Maria, S.; Kaneyoshi, H.; Matyjaszewski, K.; Poli, R. Chem.-Eur. J. 2007, 13, 2480;(b) Santhosh, K.; Gnanou, Y.; Champouret, Y.; Daran, J.-C.; Poli, R. Chem.-a Eur. J. 2009, $15,4874$.

9. Zhao, Y.; Dong, H.; Li, Y.; Fu, X. Chem. Commun. 2012, 48, 3506.

10. Debuigne, A.; Morin, A. N.; Kermagoret, A.; Piette, Y.; Detrembleur, C.; Jérôme, C.; Poli, R. Chem. - Eur. J. 2012, DOI: 10.1002/chem.201201456.

11. Heuts, J. P. A.; Forster, D. J.; Davis, T. P.; Yamada, B.; Yamazoe, H.; Azukizawa, M. Macromolecules 1999, 32, 2511.

12. (a) Wang, J.-S.; Matyjaszewski, K. J. Am. Chem. Soc. 1995, 117, 5614;(b) Matyjaszewski, K.; Xia, J. Chem. Rev. 2001, 101, 2921;(c) Matyjaszewski, K.; Spanswick, J. In: Matyjaszewski K and Möller M (eds.) Polymer Science: A Comprehensive Reference 2012, Vol. 3, 377 .

13. (a) Jakubowski, W.; Matyjaszewski, K. Angew. Chem. Int. Ed. 2006, 45, 4482;(b) Magenau, A. J. D.; Strandwitz, N. C.; Gennaro, A.; Matyjaszewski, K. Science 2011, 332, 81.

14. Matyjaszewski, K.; Jakubowski, W.; Min, K.; Tang, W.; Huang, J.; Braunecker, W. A.; Tsarevsky, N. V. Proc. Natl. Acad. Sci. USA 2006, 103, 15309. 
15. (a) Tang, W.; Matyjaszewski, K. Macromolecules 2006, 39, 4953;(b) Tang, W.; Matyjaszewski, K. Macromolecules 2007, 40, 1858;(c) Seeliger, F.; Matyjaszewski, K. Macromolecules 2009, 42, 6050;(d) Braunecker, W. A.; Tsarevsky, N. V.; Gennaro, A.; Matyjaszewski, K. Macromolecules 2009, 42, 6348;(e) Morick, J.; Buback, M.; Matyjaszewski, K. Macromol. Chem. Phys. 2011, 212, 2423.

16. Tang, W.; Kwak, Y.; Braunecker, W.; Tsarevsky, N. V.; Coote, M. L.; Matyjaszewski, K. J. Am. Chem. Soc. 2008, 130, 10702.

17. Magenau, A. J. D.; Kwak, Y.; Schröder, K.; Matyjaszewski, K. ACS Macro Lett. 2012, 508.

18. Schröder, K.; Mathers, R. T.; Buback, J.; Konkolewicz, D.; Magenau, A. J. D.; Matyjaszewski, K. ACS Macro Lett. 2012, 1, 1037.

19. (a) Le Grognec, E.; Claverie, J.; Poli, R. J. Am. Chem. Soc. 2001, 123, 9513;(b) Stoffelbach, F.; Poli, R.; Maria, S.; Richard, P. J Organomet Chem 2007, 692, 3133.

20. Braunecker, W. A.; Itami, Y.; Matyjaszewski, K. Macromolecules 2005, 38, 9402.

21. Shaver, M. P.; Allan, L. E. N.; Gibson, V. C. Organometallics 2007, 26, 4725.

22. Allan, L. E. N.; MacDonald, J. P.; Reckling, A. M.; Kozak, C. M.; Shaver, M. P. Macromol. Rapid Commun. 2012, 33, 414.

23. Matyjaszewski, K.; Woodworth, B. E. Macromolecules 1998, 31, 4718.

24. (a) Kinoshita, I.; James Wright, L.; Kubo, S.; Kimura, K.; Sakata, A.; Yano, T.; Miyamoto, R.; Nishioka, T.; Isobe, K. Dalton Trans. 2003, 1993;(b) Goj, L. A.; Blue, E. D.; Delp, S. A.; Gunnoe, T. B.; Cundari, T. R.; Petersen, J. L. Organometallics 2006, 25, 4097.

25. Fischer, H.; Radom, L. Angew. Chem. Int. Ed. 2001, 40, 1340.

26. Tang, W.; Tsarevsky, N. V.; Matyjaszewski, K. J. Am. Chem. Soc. 2006, 128, 1598.

27. Jastrzebski, J. T. B. H.; van Koten, G., Structures and Reactivities of Organocopper Compounds in Modern Organocopper Chemistry, Krause, N., Ed. WILEY-VCH: Weinheim, 2002.

28. (a) Navon, N.; Golub, G.; Cohen, H.; Meyerstein, D. Organometallics 1995, 14, 5670;(b) Navon, N.; Cohen, H.; Meyerstein, D. Inorg. Chem. 1997, 36, 3781.

29. Buback, M.; Kurz, C. H.; Schmaltz, C. Macromol. Chem. Phys. 1998, 199, 1721. 
Table of Contents graphic.

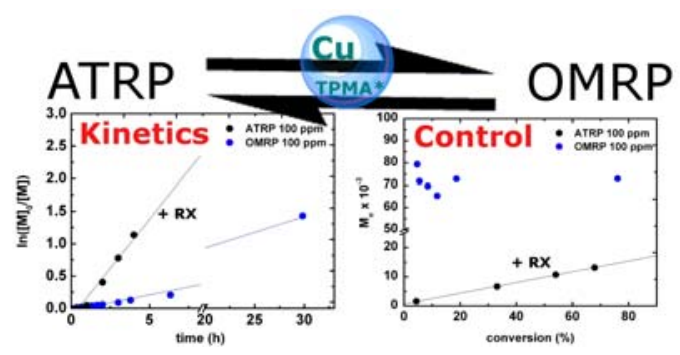

19

20

21

22

23

24

25

26

27

28

29

30

31

32

33

34

35

36

37

38

39

40

41

42

43

44

45

46

47

48

49

50

51

52

53

54

55

56

57

58

59

60 